\title{
A logged forest in Borneo is better than none at all
}

SIR - We welcome your encouragement for integrating conservation with other land use in Borneo ("Timber and tapirs" Nature 446, 583-584; 2007). However, your picture of rampant logging and forest destruction in Indonesian Borneo (Kalimantan) requires modification. Many Indonesian timber companies now contribute to conservation.

About $10 \%$ of Borneo is under strict protection. If no more than this forest is maintained, habitat loss and fragmentation will have a severe impact on many rare and wide-ranging species such as the Bornean clouded leopard Neofelis diardi, or the endangered Storm's stork Ciconia stormi. Maintenance of any additional forest offers numerous potential conservation benefits.

With half of Borneo's remaining forests, about 200,000 square kilometres, under active forestry concessions, these areas are of key conservation importance. For example, we estimate that $75 \%$ of the Bornean orangutans Pongo pygmaeus live in forest concessions. Given political realities, extensive forest areas will endure only if they yield economic benefits. Production forestry in Borneo's rain forests is selective: only a few trees are removed from each hectare, and what remains is still forest. We recently reviewed how such practices affect Borneo's wildlife (E. Meijaard et al. Life after Logging CIFOR, 2005). We found that, for forest fauna, logged forest is considerably better than no forest.

Strict protection status currently makes little difference to forest loss in Kalimantan (L. M. Curran et al. Science 303, 1000-1003; 2004). This reflects the challenge of patrolling and managing extensive areas with limited resources. In contrast, many timber companies have the capacity to manage and protect large areas of forest - and it makes good business sense to do so.
Timber companies wish to access the burgeoning 'green market' in certified timber. Four Indonesian natural forest concessions have already achieved internationally recognized Forest Stewardship Council standards, and more are trying to do so. This demonstrates a commitment to conservation-friendly management. Our monitoring of one of these concessions implies forest losses below $0.1 \%$ per year, compared with the Kalimantan average of $2 \%$ (D. O. Fuller et al. Conserv. Biol. 18, 249-254; 2004).

We urge wider recognition and support for such conservation hopes. Without this support, forests will continue to disappear. Erik Meijaard ${ }^{\star}$, Douglas Sheil $\uparrow$

*The Nature Conservancy, Indonesia Forest Program, Balikpapan, East Kalimantan, Indonesia †Center for International Forestry Research, Bogor, West Java, Indonesia

\section{Millennium: invest in country statistical systems}

\section{SIR - Your Editorial "Millennium} development holes" (Nature 446, 347; 2007) is timely in highlighting the complexities of monitoring the ambitious development goals on which the world is focused. As you note, the uneven quality of data means that our confidence in reported or predicted achievements varies by country and by indicator. Your call for more investment in evidence-based approaches is welcome, but the solutions are more complicated than this.

A significant handicap in a country's efforts to evaluate interventions is the requirement, by multiple agencies, to monitor multiple indicators for multiple internationally led projects. Its scarce resources can be undermined by the creation of parallel reporting structures, by demands for overlapping surveys for different purposes, and by financial support that is skewed to meet the donor's needs to report internationally. This results in an everwidening gap between national capacity and international expectations, and the influx of more international experts to fill the 'holes'.

Agencies and donors want national estimates of Millennium Development Goal indicators in order to make international comparisons and to monitor their investments. Because the underlying country data are often weak, agencies develop predictions or estimates to fill data gaps. But countries need more than national averages; they require intimate knowledge of changing disparities in indicators of access and outcomes, by administrative areas and between socio-economic groups. This knowledge can be gleaned only from empirical data collected through information systems that are reliable at sub-national level.

Additional investment is required, but it should be directed to supporting countries' efforts to strengthen their own statistical systems in order to produce the evidence they need nationally and sub-nationally. Until international agencies agree to provide coordinated support, the disparities will remain unnoticed and the 'holes' unfilled. Sarah B. Macfarlane ${ }^{\star}$, Madeleine Thomson ${ }^{\prime}$, Carla L. AbouZahrt;

*Global Health Sciences, University of California, San Francisco, Box 0443, 3333 California Street, San Francisco, California 94143, USA †International Research Institute for Climate and Society, Earth Institute at Columbia University, New York, New York 10964-8000, USA †Health Metrics Network, World Health Organization, 27 Avenue Appia,

1211 Geneva 27, Switzerland

\section{Millennium: big effort has produced statistical results}

SIR - Your Editorial "Millennium development holes" (Nature 446, 347; 2007) states correctly that better data are needed to track progress towards the Millennium Development Goals. In 2002, the United Nations secretary-general mandated UN agencies and other international organizations to provide the best available data to monitor progress toward the agreed goals. It became immediately evident that, as you state, many countries lacked the capacity to produce and report the necessary data.

Now, all but 17 of the countries involved have trend data for at least half the indicators.
The international agencies to which you refer carefully review available national data sources used in compiling the indicators, and formulate methodologies when estimates are needed to assess trends in the various regions. These methodologies are then reviewed by international and national experts.

Data gaps have been clearly identified, and efforts to assist countries in the production and use of the necessary data have been scaled up. Statisticians from UN member countries have also reviewed the quality and availability of data to monitor the goals and have provided recommendations. At the 2006 and 2007 meetings of the UN Statistical Commission, a forum for the heads of national statistical systems, more than 130 countries reported on their progress in implementing these recommendations. Although noting that deficiencies still exist, the commission agreed that real progress has been made, and called for improved funding and political commitment to support the development of statistics. We believe the national and global statistical systems have benefited immensely from these efforts.

The global statistical system has made a huge effort to improve data quality and availability, from helping to conduct censuses and surveys in difficult areas to improving vital registration systems. This has produced visible results.

In addition, rather than using lack of data as an excuse for inaction, many countries have increased the use of existing data to prepare and implement goal-based strategies and to conduct rigorous research and assessment of their programmes.

\section{Paul Cheung}

United Nations Statistics Division, 2 UN Plaza,

DC2-1670, New York, New York 10017, USA 